\title{
1 Containment and Empathy in Katherine Mansfield's and Virginia Woolf's Short Stories
}

\author{
Laura Oulanne
}

she could see little bits of her yellow dress in the round looking-glass which made them all the size of boot-buttons or tadpoles; and it was amazing to think how much humiliation and agony and self-loathing and effort and passionate ups and downs of feeling were contained in a thing the size of a threepenny bit.

(Woolf 54)

Human beings are often conceptualized as containers for thoughts and feelings. We see ourselves, in theory and in everyday life, as vessels further contained by the clothes and built spaces we inhabit, yet in fact our experience may extend to encompass these material containers and the world beyond them. Clothes and material spaces can separate bodies and minds from one another and create spaces of isolation; however, in the two short stories discussed in this essay, containment also becomes associated with relationality and affective connection. "Miss Brill" (1920) by Katherine Mansfield and "The New Dress" (1927) by Virginia Woolf exemplify modernist thematics such as the limits of knowledge, empathy, and sympathy between human beings, but they also have a less frequently addressed focus on the affective relationship between human characters and nonhuman things and spaces. The stories invite empathetic engagement even if their characters, like Woolf's Mabel Waring above, describe themselves as "things" verging on nonhuman. I propose that the "passionate ups and downs of feeling" that the reader of these stories is invited to engage with do not appear as the property of individual minds sealed off from others, but as affects that arise in the encounters of human and nonhuman bodies.

This essay aims to point out the formal and affective affordances of the texts for an anti-anthropocentric understanding of empathy, affectivity, and the mind. By describing the formal features of a text, as exemplified recently by the work of Caroline Levine, it is possible to make visible the way meanings are constrained, but also enabled, by literary forms. Similarly, from a cognitive perspective explored by Terence Cave, "redescribing" literary texts from the point of view of their affordances for conceptual and embodied sense-making yields insight into the plurality of interpretation. I take affect, which both Cave's and 
Levine's accounts of form and affordance risk overlooking, to be an integral part of the literary form. This essay "redescribes" the affective form and content of Mansfield's and Woolf's short stories to investigate the phenomena of containment and empathy that the stories set in conversation with one another. My readings suggest that containment as a material condition and a literary form elicits empathy, while it does not work as a model for the mind or the human individual. Thereby I also take a step toward a new reading of empathy and solipsism in modernist fiction.

Containment is a way of both conceptualizing and experiencing space. Here the term is used in three senses: concrete, material container-spaces such as rooms, boxes, and clothes in the fictional worlds of the two stories; containment as a schema of embodied origin involved in thinking (conceptualizing time, life, or the human individual as a container, for instance); and containment as a formal feature of narratives, manifested in circular structures and closure. These senses are interconnected: the metaphorical use of the schema in abstract thinking is based on our everyday experience of concrete containers (Lakoff and Johnson 2) ${ }^{1}$ and the understanding of stories as containers of events and meaning draws on such schematic thinking. Katrin Dennerlein suggests that containment is our main way of conceiving of space in fiction, based on the evolutionary importance of container spaces (62); on the other hand, relying merely on this schema risks affirming an anthropocentric focus and neglecting dynamic and networked models of space, as has been shown by Marlene Karlsson Marcussen (60). The following readings show that the schema of containment also affords non-anthropocentric, dynamic and relational understandings of space, reading, and experience. ${ }^{2}$

The conceptual areas of empathy and sympathy have been tangled since the early uses of both terms. "Sympathy" predates "empathy" and began to take on its contemporary distinctive meaning, namely "feeling for" as opposed to "feeling with" or "feeling into" (Einfühlung), around the time of writing of the modernist texts studied here. Within the limits of this chapter, it is not possible to delve into the conceptual nuances, and empathy is here used as an umbrella term for a variety of phenomena of intersubjective affectivity involving a sense of "feeling with." However, I draw especially on phenomenological approaches ${ }^{3}$ that focus on empathy as a sense of another's feeling or mood gained by virtue of their embodied expression (Zahavi 55, Zahavi and Rochat 545). To encompass even nonhuman bodies, Jane Bennett's work on the notion of sympathy in Walt Whitman's poetry offers an opportunity to broaden this complex notion to involve nonhuman spaces and things. A focus on embodiment and the challenge to views of empathy as projection, amalgamation of minds, or conscious mind-reading complements the discussion of empathy in fiction-especially when the position of the nonhuman world is foregrounded.

These approaches to fellow-feeling allow for a new point of view into the discussion of empathy and modernist fiction. Meghan Marie Hammond 
has charted the preoccupation of modernist writers with the "problem of other minds," producing texts that discuss forms of fellow feeling but being "never at ease" with it $(1-2,20)$. Kirsty Martin discusses sympathy in modernist fiction as a multifaceted, cognitive and embodied phenomenon and also points out moments of sympathy with the nonhuman world depicted by Woolf, Vernon Lee, and D.H. Lawrence. Martin reads emotion as a cognitive phenomenon as a bridge between the individual and the (material) world and shows how the authors, contrary to some received notions, are engaged with sympathy but portray the affective relations between the individual, others, and the world as troubled and ethically challenging $(10,16-17)$. Both studies draw on a variety of theories of empathy and note modernist writers' resistance to mind-body dualism (Hammond 54, Martin 24). Yet they often resort to a cognitivist model of emotion centered around the human individual, which also appears as the basis of the ethical problematic of empathy and sympathy. I propose that the investigation of sympathy and empathy in modernism could profit from the comparison of phenomenological and new materialist approaches to empathy and sympathy as an alternative to thinking through internalist and individualist metaphorical language, which many modernist authors, too, seem to be struggling away from. I follow Martin in drawing attention to the way the texts I read actually display multiple forms of affective interaction between the human and the nonhuman, realized in an experience of lived space and bodies, but suggest that the stories support approaches to empathy that may remain ethical without privileging the human individual.

Like Martin, Bennett addresses the vitalist tradition of sympathy in noting that in addition to a moral sentiment akin to pity, sympathy has persistently been described as a "vital force operating on bodies from without," a "more-than-human atmospheric force," and it is as such as it often appears in the poetry of Walt Whitman (Influx \& Efflux 27, 29). Additionally, early uses of the notion of "empathy," including its firs English usage in the psychological aesthetics of Vernon Lee, often actually discuss empathetic relations between humans and nonhuman objects (Lee, Beautiful 61-69, Martin 46, Titchener 417). ${ }^{4}$ Furthermore, phenomenological studies of the related phenomenon of affective incorporation have shown how nonhuman, inanimate things such as clothes and instruments are involved in affective states, not solely as objects of intention but as parts of the human lived body, as it were; things may enforce or sustain an affective state but also contribute to its emergence (Colombetti 238-41). The upshot of all these approaches is that affects arise not (only) from an individual psyche, but in interaction with others and also with spaces and things, by virtue of the embodied being-in-the-world that defines human experience. This also changes how the "sharing" of affect can be understood.

This point of departure is in line with David Herman's observation of modernism as not an inward turn but a turn outwards, toward the lived world. According to Herman, "mental states have the character they do 


\section{Laura Oulanne}

because of the world in which they arise, as a way of responding to possibilities (and exigencies) for acting afforded by that world" (253). Thereby the "problem of other minds" in modernism should not merely be seen as based on the access to or the inscrutability of emotions hidden within the individual, but an issue of how human and nonhuman existents share the lived world. Instead of repeating the metaphor of the human being as a sealed container for emotions, I suggest that we pay attention to "actual," material container-spaces in the fictional worlds of the stories and their affordances for imaginative, affective engagement, as well as to the affordances of the literary form as a container. This shift reveals how they work to construct affective forms of intersubjectivity/interobjectivity that suggest an ethical alternative to the dualist model of the individual sealed off from the world.

\section{Mansfield's Boxes, Cupboards, and Universal Empathy}

Katherine Mansfield is known for her creative, impressionistic experimentations with the short story form. As Ellen Burton Harrington suggests, many modernist short stories are spatial rather than temporal pieces of fiction and foreground the description of a situation over a succession of events (5). Therefore they are intriguing from the point of view of the container as a material and literary form. The relationship between empathy and short fiction has been seen as a difficult one: short stories often frustrate the reader's desire to feel with characters, and several researchers have characterized Mansfield's work as stories of separation and alienation (Hammond 91, 94; Head 110; Kokot 71). I am proposing an alternative reading of a popular story by Mansfield, in which a sense of universal community, however problematic, emerges beside the isolation of human individuals by virtue of the form of the story and its depiction of material spaces. $^{5}$

"Miss Brill" is narrated in third person but speckled with free direct and indirect discourse, focalized by the eponymous English teacher living in a French town. The story is a brief account of her Sunday visit to a public park. Its discourse begins when Miss Brill is already outdoors, but it recalls her earlier departure from her apartment, which has involved putting on a piece of fur. In the park, Miss Brill follows the actions of her fellow strollers with keen, compassionate interest, which grows into a sense of blissful unity and belonging she feels when listening to a band. The ecstatic moment is cut short when she overhears a young couple making abusive comments about her; she promptly returns home, passing by the bakery she usually delights in visiting on Sundays, and puts the fur back into its box.

Only at the end of the story do we learn more details about Miss Brill's apartment: it is described as a "little dark room" and compared to a cupboard (Mansfield 114). The parallelization of living quarters and a cupboard has already occurred slightly earlier, as Miss Brill reflects on the other people in the park: "They were odd, silent, nearly all old, and from the way 
they stared they looked as though they'd just come from dark little rooms or even-even cupboards!" (111). The short story is structured as a series of movements between fictional spaces, which coincide with the affective structure of the text: out of small, nested containers toward an open space accompanied by a liberated feeling; a rupture in this experience and a swift movement back into the containing space. The dominant impression of its whole, formed retrospectively, is a circular structure consisting of in-andout movements in space rather than a linear progression. Thus, the form of the story resembles the containers presented in it.

The beginning of the story foregrounds both Miss Brill's special relationship with a nonhuman thing and the presence of concrete container spaces:

Miss Brill put up her hand and touched the fur. Dear little thing! It was nice to feel it again. She had taken it out of its box that afternoon, shaken out the moth-powder, given it a good brush, and rubbed the life back into the dim little eyes. "What has been happening to me?" said the sad little eyes.

The small fur is a "dead" thing that retains some of its earlier animal shape. It is animated in Miss Brill's imagination: life can be rubbed "back into" its glass eyes, and emotions and verbal thoughts are attributed to it. It is not given life as the animal it once was, but rather personified as a thing to which human language is attributed; thus, there is an ontological instability to the core of the affectionate relationship between Miss Brill and the fur. It is also clear from the beginning that the fur participates in the affective structure of the story built around experiences that can be read into its human protagonist. The "actual" feelings of Miss Brill could be seen as either psychologically projected onto the fur or metonymically expressed by this leitmotif. I suggest that the "feeling with" that occurs between the woman and nonhuman things is actually at the core of the affective experiences evoked in the story. Phenomenologically considered, clothes are minimal containing spaces for the human body, yet they can also be incorporated into affective experience (Colombetti 238-41). The fur is carried close to the body and can be imagined to form part of the everyday clothes defining the body's outline, yet Miss Brill also engages with it as a separate thing. In both cases, it is an integral part of the feelings Miss Brill goes through as the story progresses.

The cupboard-space of Miss Brill's home and the box-space that is home to her animated fur are contrasted with the atmospheric phenomena of joy and openness of the park, all acted out between human beings and nonhuman things. When approaching the park, stroking her fur, Miss Brill feels something "sad—no, not sad exactly—something gentle" moving in her bosom. In the park, she notes that "the band sounded louder and gayer" 
(Mansfield 110) than on other Sundays and wonders whether the conductor is wearing a new coat; things appear more festive than usual. Miss Brill extends the affectionate interest she displayed for her fur to other people, who also become defined by clothes. There is a meeting between characters she calls an "ermine toque" and "a gentleman in grey," which ends in the gentleman humiliatingly snubbing the lady, all of which Miss Brill follows with fascination. The people appear to her as actors in a play, and they are typified by way of naming them according to their clothes. Thus the story, via Miss Brill's focalization, performs gestures of dehumanization. Miss Brill is parallelized with the reader who follows the events possibly with a degree of narrative empathy for the characters, yet remains distant from them. Neither she nor the reader gain knowledge of the "true" experiences of the ermine toque or the gentleman in grey. Nonetheless, the crowd seems capable of arousing her emotional interest and engagement, expressed in exclamations like "Dear me!" and "Oh, how fascinating it was! How she enjoyed it!" (112).

The affective tones of the story do not rest only on performance and spectatorship, however. Miss Brill's focalization displays a sensitivity to sensory experience and synesthetic connections, all of which contribute to the affective structure of the story. After witnessing the mistreatment of the "ermine toque," she senses reciprocation in music: "But even the band seemed to know what she was feeling and played more softly, played tenderly, and the drum beat, 'The Brute! The Brute!' over and over" (112). The "knowing" in the sentence can evoke a cognitive account of empathy based on conscious mind-reading, although the "knower" is a collective entity. On the other hand, empathy is "heard" in the beat of the personified drum, which in Miss Brill's mind connects with how she is feeling. ${ }^{6}$ In "Miss Brill," instead of metonymically representing empathy-as-knowing in the form of music, a more affective form of empathy is built between the focalizer, the band, and the players in the scene she has just witnessed, all assemblages of human bodies and nonhuman things.

This presentation of affectivity distributed between human and nonhuman entities becomes more explicit in what follows the ermine toque scene. Miss Brill experiences a blissful moment of universal love and empathy, tuned to and paced with the music and the materiality of the fictional space:

The band had been having a rest. Now they started again. And what they played was warm, sunny, yet there was just a faint chill-a something what was it? - not sadness—no, not sadness—a something that made you want to sing. The tune lifted, lifted, the light shone; and it seemed to Miss Brill that in another moment all of them, all the whole company, would begin singing. The young ones, the laughing ones who were moving together, they would begin, and the men's voices, very resolute and brave, would join them. And then she too, 
she too, and the others on the benches-they would come in with a kind of accompaniment-something low, that scarcely rose or fell, something so beautiful-moving. ... And Miss Brill's eyes filled with tears and she looked smiling at all the other members of the company. Yes, we understand, we understand, she thought-though what they understood she didn't know.

By virtue of its relative length and evocations of spaciousness and light, this section adds a feeling of "largeness" into the middle part of the story. Its gradually inflating expression is full of long, open-ended phrases and repetitions. Embodied metaphors of upward movement are attached to the music and light imaginable in the space of the park and build a connection between the listener and the world, much in the way Vernon Lee's contemporary work on aesthetic empathy describes the relationship of a listener to music, in which "I also, being identified with the sound, having become apparently the sound itself, must needs move and soar with [the notes]" (Lee, Laurus Nobilis 15; see Martin 42).

This kind of description of aesthetic empathy complicates the reading of the passage and the story as a depiction of cognitive isolation. The affective value of the experience for Miss Brill is evoked by the description of her embodied reactions and by thought report. "We understand" is the content of her thoughts, but it is worth noting that its meaning is different from propositional "knowing." Miss Brill not "knowing" what they "understood" can be interpreted ironically, as if the narrator/implied author was displaying the flimsy grounds of her attunement with the world and others, to which she really has no access. However, the entire passage preceding the phrase builds a non-individualistic, externalist account of this understanding, inviting the reader to join in: it grows out of the music and the atmospheric, material qualities of the situation, instead of being the property of the protagonist's erring mind. The music is "moving," the group "move together," and the understanding between them is of a nonverbal kind. The fact that the language of the story cannot directly express it testifies less of the limits of knowledge and understanding and more of the limits of language, yet the literary text seems capable of conveying even what Miss Brill cannot directly express.

The blissful moment becomes thwarted when Miss Brill overhears the young couple call her a "stupid old thing" and even insult her fur, which to them looks like "a fried whiting" (Mansfield 113). The final part of the story consists of the narrator reporting Miss Brill's actions, no longer her thoughts or feelings. She leaves the park and goes straight to her room, to sit still for a long time, and finally ("quickly, without looking”; Mansfield 114) lays the fur back in its box. The story ends with an observation: "But when she put the lid on she thought she heard something crying" (Ibid.). Thus, in the semiotic field of "Miss Brill," containment does not point toward safety 


\section{Laura Oulanne}

and happy memories as it does in Gaston Bachelard's influential Poetics of Space (1958), for instance, but toward constraint and suffocation. The ending, with Miss Brill returning to her "cupboard" and the fur returning to its box, to be stored within an actual cupboard nested within the apartment space, affords at least a twofold "closure" enacted by the material features of the storyworld and the progression of the events.

In this light, the ending might be read as supporting an ironic, internalist interpretation, as a reminder that there has been no actual connection between any of the agents of the story, and everything happens "inside" Miss Brill's mind. This is a formal feature very typical of Mansfield's stories. There may be a moment of epiphany, felt as an opening, but it tends to be followed by a blunt, negative anti-epiphany, even though her stories are usually read more in terms of open-endedness than closure (New 106, 124). The propositional "message" of the story seems clear: Miss Brill is like her fur, trapped inside a box of her life and mind, and so are the other people in the park. Her sense of "singing together" and "moving together" has been an illusion, and only her exalted mood has kept her from seeing the true state of things-people as containers sealed off from one another.

However, if we consider the whole of the story in terms of its form, the meanings it affords are not quite sealed by its closure, and its celebration of a universal kind of bodily empathy or material sympathy is not negated by the fact that the story ends by placing its main character in isolation. Caroline Levine warns of conceiving literary texts as spatial artifacts, suggesting that it is their temporal form that affords other than totalizing meanings. The form of "Miss Brill" is temporal in terms of progression but rather circular than linear, which makes the moment of ecstasy in the park appear as a peak or an opening in the circle. The closure meets the beginning, not constructing an opening into futurity akin to what Levine has in mind, but a containment of the story within itself, including all the smaller, concrete containers of the fictional world. What remains with the reader is a conceptual-experiential blend of containments and openings, but the affective weight of the ecstatic description in its middle positions all these containers as something that affords an opening. Thereby even the ending retains some of the openness of the middle part and does not need to cancel the nonpropositional "understanding" achieved there.

The story confirms an understanding of literary texts as, in Levine's words, "inevitably plural in their forms-bringing together multiple ordering principles" (40) in spite of working within the form of the bounded whole. The reader has been invited to follow Miss Brill in experiencing the intensity of being-in-the-world as being-with-others-people and things. She is also invited back to the small apartment, and further, back into the stuffy box in the cupboard, as the focalization of the story has distributed the fictional experience between Miss Brill and her furry companion. Actually none of the movements in the story are "hers" only. In the moments of connection, people do not appear as sealed containers but intensely present in an 
embodied manner, as do the nonhuman features of the storyworld. In this world, it seems possible to "feel with" a fur, a crowd of people, and a piece of music. None of this is dependent on "knowing" or even "understanding;" the sympathetic distribution of affect comes forth as an integral part of life, as Bennett puts it, "a more-than-human flow of communicative transfers, a flow that is the indispensable precursor to the interiorized sentiment that bears the same name" (Influx \& Efflux 29).

In conclusion, the story proposes the impossibility of empathy, but on the other hand, the reading of the story as an affective whole relies on a worldly kind of empathetic engagement. Metaphorically, the story itself could be described as a box containing various elements in a dynamic relation with one another. The preference of spatial description over temporal succession affords an interplay of various meanings instead of a fixed interpretation that would reveal the human condition of solipsism and the illusoriness of empathy. Even though Miss Brill's interaction with the fur may come across as a symptom of isolation, and even though her blending with human and nonhuman others seems like an illusion shattered by the reality of human meanness, the affective structure of the story hints not only at the possibility of empathy but also its being a necessary part of lived experience. As Hammond observes, Mansfield displays "human interiority [as] intrinsically networked" (111-12). To take the idea further, the networks of the story crucially involve the nonhuman world and question the entire idea of "interiority" as the defining feature of affective experience.

\section{Woolf's Yellow Dress as a Space for Empathy}

The possibilities or impossibilities of intersubjective connection and empathy are also a central theme in Virginia Woolf's fiction. As Martin notes, Woolf "explores both the feeling of the sympathy, and the sense that sympathetic connection might take place at a level removed from conscious feeling, extending beyond one's body" (82). Martin notes that Woolf experimented with rendering sympathy as a communion with the world that surpasses the individual but is wary of the ethical implications of this notion. In line with Martin's interpretation, I am reading Woolf's short story “The New Dress" as an exploration of such sympathy/empathy as a phenomenon surpassing the individual, based on embodied grasping or synchrony. Reading the formal composition of the story and its container spaces with the phenomenological perspective to embodied empathy and the idea of sympathy as a more-than-human atmospheric phenomenon, I suggest that Woolf's fiction may be read as an evocation of an anti-anthropocentric ethic, which does not necessarily privilege the contained human individual.

Woolf wrote "The New Dress" after finishing Mrs Dalloway (1925), as part of a group of eight stories all set in Clarissa Dalloway's party. Like "Miss Brill," it is an account of a social gathering from the point of view of a solitary woman. Yet as regards characters' movements in the fictional 
space, Woolf's story is structured like a mirror image of Mansfield's: it is opened by an entry into an interior space and closed by a departure from it. The story is narrated in third person but focalized by Mabel Waring, who has had a dress made for the party. The beginning of the story is marked by a rupture in her experience, initiated by an uncomfortable sense of the dress: "it was not right, not quite right ... No! It was not right" (49). The rest of the narrative relates Mabel's struggles as she interacts with other guests but simultaneously has her mind on the dress that she has deemed a failure and her recollections of trying it on at the dressmaker's. In Mabel's focalization, the main lived spaces of the story (the Dalloways' house, the dressmaker's studio, and the minimal space of the dress around Mabel's body) all appear as cramped, confined containers closing in on one. As such, they afford not only a limited set of kinesthetic actions but also limits for intersubjective engagement. However, the formal dynamics of "The New Dress" and its affective structure as experienced by the reader suggest that feelings are not all contained within characters and their restricting clothes and apartments but that spatial elements and nonhuman, material containers also bring about affective states and elicit empathy.

Readers learn that the dress is pale yellow, made of silk, with a long skirt and "high sleeves," but its description is rendered markedly subjective with the addition of "idiotically old-fashioned" (50). Mabel attributes the realization that something is "not right" to other guests' imagined thoughts, and this changes her experience of the spaces of the story: "And at once the whole of the room where, for ever so many hours, she had planned with the little dressmaker how it was to go, seemed sordid, repulsive; and her own drawing-room so shabby, and herself, going out, puffed up with vanity ... all this now seemed unutterably silly, paltry, and provincial" (49-50). This feeling is said to "explode" the moment she enters the drawing-room. Mabel's insecurity implies a class distinction between her and the Dalloways: she cannot afford a fashionable dress, so she decides to make hers special by following an old Paris fashion book, with the result of her looking different from the other guests. The dress and the drawing-room act together to change Mabel's perception of the situation, and of herself. It is impossible to say which is causally prior, her feelings about herself or her perception of the surrounding space and the effect of her dress; the two form an integral whole. As the dress keeps appearing in the story, it not only metonymically but also concretely encompasses Mabel's fictional experience and invites the reader to imagine the bodily feeling of wearing it, which can be conductive of a kinesthetic form of narrative empathy.

Mabel makes attempts toward interpersonal connection, but they seem to be thwarted by her feelings of insecurity and inferiority, which are enacted in the way she experiences her dress and the space of the drawing-room. She conjures up a mantra-like phrase, typical of Woolf's work, which she repeats to change her perspective of the party: "We are all like flies trying 
to crawl over the edge of the saucer" (50). Yet she only succeeds in seeing herself as a fly stuck in a saucerful of liquid. She also tries to put things into perspective by declaring: “There's Shakespeare! There's death! We're all weevils in a captain's biscuit'-or whatever it was that people did say" (52). Here the change from direct to indirect discourse suggests a change from the directness of exclamation to an appeal to the common opinion, Mabel remaining the focalizing agent all the while. The narration supports the impression that Mabel unsuccessfully attempts to get ecstatically "beside herself" to shed the point of view that remains tightly bound to herself; the story offers no shifts of focalization in the manner of Mrs Dalloway or Woolf's later novels.

A conversation about family illnesses continues to tweak the scale and thematize the problems of sympathy. Mabel, as quoted at the beginning, sees herself and her interlocutor in the mirror as "boot-buttons or tadpoles:"

And what was still odder, this thing, this Mabel Waring, was separate, quite disconnected; and though Mrs. Holman (the black button) was leaning forward and telling her how her eldest boy had strained his heart running, she could see her, too, quite detached in the looking-glass, and it was impossible that the black dot, leaning forward, gesticulating, should make the yellow dot, sitting solitary, self-centred, feel what the black dot was feeling, yet they pretended.

Mrs. Holman "snatches" the minimal sympathy Mabel is able to give, and Mabel thinks she is "greedy" for more-yet "in her yellow dress to-night she could not wring out one drop more; she wanted it all, all for herself" (55). The passage displays a skepticism of sympathy typical of Woolf's work. Sympathy is portrayed as a scarce substance to be dealt condescendingly between the characters, themselves closed containers; Mabel's unfortunate dress appears as a shell that covers emotions and blocks interaffective exchange. This definition of sympathy is close to the moral sentiment of pity, which suggests a hierarchical relation; it also implies two "self-enclosed" subjects who can only form imaginary "ideas" of what the other is feeling (Bennett, Whitman's Sympathies 607). However, the dehumanizing tone, referring to the characters as "this thing," "the yellow dot," suggests that the sympathy at play in the passage is not pity, but an affective assemblage whose bounds "spill out beyond the human" (612). The narrator's wording invites the reader to observe the interaction as an encounter between two bodies in space. The intersubjective exchange of the passage can thereby be seen to reside on the surfaces of the characters' bodies and in the space that they both inhabit, instead of their interior psyches. The situation, with all its difficulties, arises from its assemblage of things in space, not from an architecture of human minds nested within sealed containers. 


\section{Laura Oulanne}

Furthermore, Mabel actually senses the need for sympathy in her interlocutor, and the gestures of the "black dot" are provided as proof of this need. Following Dan Zahavi and Philippe Rochat, the bodily expression of another-even as a "gesticulating" "black button"-allows us to grasp something of their affective state. This is an intersubjective relation that the reader of the story is invited to participate in. The idea of gaining the knowledge of the other's need by "reading" or forming "ideas" may therefore be too restricted. The reader is indeed reading a text, but the passage invites the involvement of pre-reflective processes that are closer to the minimal affective, kinesthetic grasping of the imagined, fictional body and, crucially, the material containers encompassing/incorporated in it. It is this kind of "reading" that could be applicable to the instance of "mind-reading" evoked in the fictional world as well, which foregrounds the relational and the nonhuman as sites of emotion besides the rational human container of thoughts and emotions.

In another space, the dress is shown to function quite differently, as an element of distributed affectivity. The dressmaker's workroom is brought up twice in the story. When first mentioned, it is presented as an alternative, illusory reality revealed as such by the space of the Dalloways' drawing-room:

This was true, this drawing-room, this self, and the other false. Miss Milan's little workroom was really terribly hot, stuffy, sordid ... yet, when Miss Milan put the glass in her hand, and she looked at herself with the dress on, finished, an extraordinary bliss shot through her heart. Suffused with light, she sprang into existence.

(Woolf 51)

Paradoxically, in the stuffy room, expressions of containment give way to those of light, openness, and the existential feeling of being alive. Again the text points toward a material surface, a reflection of a dress in a mirror, yet Mabel describes seeing "the core of herself, the soul of herself" (51-52). Importantly, she is not alone in her bliss:

she felt, suddenly, honestly, full of love for Miss Milan, much, much fonder of Miss Milan than of any one in the whole world, and could have cried for pity that she should be crawling on the floor with her mouth full of pins, and her face red and her eyes bulging-that one human being should be doing this for another, and she saw them all as human beings merely, and herself going off to her party, and Miss Milan pulling the cover over the canary's cage, or letting him pick a hemp-seed from between her lips, and the thought of it, of this side of human nature and its patience and its endurance and its being content with such miserable, scanty, sordid, little pleasures filled her eyes with tears. 
This moment of epiphany resembles the one described in "Miss Brill," even as regards the exact choice of words ("filled her eyes with tears"). Love, a sense of togetherness, and the problematic moral sentiment of pity mingle with the perception of the other's bodily experience of crawling on the floor and expand into a vision of interconnectedness involving human beings and Miss Milan's canary, a vision that Mabel's spells do not manage to retrieve in the party space. Even though the material features of the two situations are almost identical (the dress, a mirror, two women), the workroom hosts a completely different feeling than the drawing-room. Is this a product of mere sense of socio-economical superiority, which Mabel is not able to attain at the Dalloways' party? This is a plausible reading, and Woolf's story certainly suggests that to "have" sympathy or empathy one needs certain material affordances. Yet the dominant affective tone of the passage is not of superiority but of an abstract love that encompasses Mabel, canaries, seamstresses, and party-goers alike, and a giver or a receiver of sympathy cannot be identified.

Woolf's story seems to debate the problem of empathy as an epistemological question of truth and illusion. Mabel is wavering between the view of the party as "true" and her bliss at the dressmakers' as illusion; on the other hand, "Miss Milan was much more real, much kinder" (53). None of the options sticks with Mabel affectively, which she attributes to her "vacillating character." If we read "The New Dress" as a study of how this type of personality colors perception, the epistemological outcome would be along the lines of the subjectivity of all truths. However, the affective-cognitive engagement the story invites suggests a more spatial and relational, less relativist reading. The two rooms and the dress are brought forth as material frames for all Mabel's musings, and the story foregrounds their effect on Mabel's experience in all its ambiguity, which is not only epistemological but also ontological: "a party makes things either much more real, or much less real," she contemplates (51). It is not only Mabel's "personality" that should be taken into account in reading the text from the point of view of affect and empathy, but also the relations between bodies in space, which come to the fore in the form of the story.

Even though the actual events are located in the party, Mabel's thoughts bring up other spaces. In addition to recollections of her own drawing-room and Miss Milan's workroom, she remembers a "divine moment" on the seaside and plans a visit to the London Library; the two spaces become parallel in terms of openness and possibility. She describes feeling on the beach as though she was lying "in the hand of the Goddess who was the world" (56) and rejoices in the possibility of finding a life-transforming book at the library. Punctuated with these images, the story follows Mabel's embodied mind in oscillating between containment and liberty, stuffiness and openness, all the while remaining in Clarissa Dalloway's drawing-room and within the yellow dress, which indeed is capable of containing all the imaginary spaces and "ups and downs of feeling" that the story is built on. 


\section{Laura Oulanne}

Although "The New Dress" is less clearly organized around a path from containment to opening and back than "Miss Brill," this story too ends in a material enactment of closure: as Mabel leaves the party, devastated, she wraps herself "round and round and round, in the Chinese cloak she had worn these twenty years" (58). Readers are given strong cues to follow Mabel's focalization through alternating experiences of suffocation and rapture, as concrete experiences and embodied metaphors. The tightness of the cloak and its thrice repeated enclosure of Mabel's body give experiential form to the closure of the story, but on the other hand, the ending has her exiting the interior space into the world of beaches and libraries. Taking into account the status of the story as a fictional narrative, and even one with a shared storyworld with Mrs Dalloway, the closure does not mark a totalized meaning.

Furthermore, "The New Dress," even more so than "Miss Brill”, could be described as a container without losing the possibilities of openness and ambiguity. The story does not rely on a climax of plot. It is a descriptive account of impressions for which the container metaphor is quite fitting, especially if we recall what containers are like in its storyworld: not abstract but lived, material spaces. The "plot" of the story consists in slight affective shifts in fictional lived space, which do not follow any particular order or display a pattern of development. Rather, their alternation is brought to the fore, which seems to make ambiguity and relationality, rather than solipsism and containment, the "final words" of the story. The story, like the party, has afforded experiences that feel both intensely real and shallow or deceptive.

Understanding "The New Dress" as a container of narrative experience affords two levels of reading. On the one hand, the story is organized around a timeline from Mabel's entrance to her exit contained within her cloak and read accordingly as an account of existential loneliness; on the other hand, it can be seen as a more ambiguous stream of affectivity, which experientially suggests the possibility of empathy and distributed affect that is denied by the propositional content. The blissful, exultant moments of being, accompanied by a sense of opening up, are suggested to be as experientially "real" as the moments of doubt and segregation at the party. Thereby the focus shifts from questions of peering into the minds of others to the way things and bodies exist and share space, and the human individual is removed from its center. The eponymous dress is a nonhuman thing, yet central to the production of the affective complexity of the story. Its material properties, too, afford two opposing interpretations: it is a tight, stuffy, and "wrong" container for the human body, but its color and material point toward light and lightness. It is ambiguous in its relation to intersubjective connection, both in the storyworld and as a narrative device. In the fictional world, the dress is a barrier between Mabel and others, but it also affords empathy. In line with the phenomenological account of empathy as embodied grasping, it seems to be the expressiveness of other bodies, clad in dresses of different colors, sometimes seen only in the mirror as dehumanized dots, that elicits 
what can be sensed of the feeling of the other. The reader, too, is continuously reminded of the feelings brought forth by the materiality of the dress and invited to empathize with Mabel's embodied experience, not so much with the report of her thoughts. In "The New Dress," the ontological and physical closeness of human characters and nonhuman things is therefore not an obstacle to but a vehicle of empathy.

\section{Conclusion: Feeling Into Containment}

"Miss Brill" and "The New Dress" foreground the importance of material spaces and nonhuman things for affectivity and intersubjectivity. They display psychologistic empathy and the "moral sentiment" of sympathy as highly problematic phenomena laden with power imbalances, yet present intense moments of empathy as a fellow feeling, grasping something shared in being-in-the-world between human and nonhuman entities. Seen thus, the account of the mind put forth in the stories is not one of subjective interiority, but of embodied being in an experiential world. The stories show humans contained by material spaces, but do not display the human individual as a container sealed off from the world.

This reading of the relation between the metaphor of the container and the modernist "problem of other minds" opens up new ways of thinking about the container form in literature. The mind or consciousness emerges from overlapping schemas of containment in the material world. In the storyworlds, words often come between the characters as barriers rather than something that brings them together, while material things and bodies constitute connecting surfaces as well as separating boundaries. Considering the stories as fictional artifacts made sense of in a process by an embodied reader, their spaces and materialities, as well as the lived bodies come to the reader by way of words. The stories' way of using containers as cues for imagining what it is like to be the character in the fictional, material world, and as schematic metaphors based on the shared experience of that world, does not suggest a container view of the mind but conversely a relational, interconnected, entangled existence of human and nonhuman bodies. Furthermore, the container as a spatial metaphor for the form of a short story, or of fiction in general, affords not only immobility and totality but also ambiguity and openness of meaning.

\section{Notes}

1 According to Lakoff and Johnson, conceptual metaphors that dominate our thinking arise from the way our lived bodies interact with the world: in addition to a vertical position and a forward-looking face, for instance, our bodies are experienced as containers separated from the environment by the skin, and themselves capable of being contained.

2 This direction has been explored in earlier fiction by Miruna Stanica (2014), according to whom the description of space as a container leads to a 


\section{Laura Oulanne}

non-anthropocentric, aperspectival relation to fictional space, and a focus on containers enables the mobility of characters instead of fixing them in terms of time, space, or meaning.

3 These approaches, however, build on the work of thinkers contemporary to Woolf and Mansfield, such as Edith Stein and Max Scheler.

4 Edward Titchener understands empathy to be, among other things, a "process of humanising objects;" Vernon Lee's account of aesthetic empathy discusses a projective relation between a human viewer and a work of art or a landscape.

5 For a reading of empathy in this story in conjunction with other works by Mansfield, in addition to Jean Rhys's short fiction, see Oulanne 2021.

6 Music, arising in an interaction between a musician and a thing — an instrumenthas been shown to enhance and produce affectivity by itself (Colombetti 242).

\section{References}

Bennett, Jane. Influx \& Efflux: Writing Up with Walt Whitman. Duke University Press, 2020.

Bennett, Jane. “Whitman's Sympathies.” Political Research Quarterly, vol. 69, no. 3, 2016, pp. 607-20.

Cave, Terence. Thinking with Literature: Towards a Cognitive Criticism. Oxford University Press, 2016.

Colombetti, Giovanna. “Affective Incorporation." Phenomenology for the TwentyFirst Century, edited by J. Aaron Simmons, and J. Edward Hackett, Palgrave Macmillan, 2016, pp. 231-48.

Dennerlein, Katrin. Narratologie des Raumes. De Gruyter, 2009.

Hammond, Meghan Marie. Empathy and the Psychology of Literary Modernism. Edinburgh University Press, 2014.

Harrington, Ellen Burton. Scribbling Women and the Short Story Form: Approaches by American and British Women Writers. Peter Lang, 2007.

Head, Dominic. The Modernist Short Story: A Study in Theory and Practice. Cambridge University Press, 1992.

Herman, David. "1880-1945: Re-Minding Modernism." The Emergence of Mind: Consciousness in Narrative Discourse in English, edited by David Herman, University of Nebraska Press, 2011, pp. 243-72.

Kokot, Joanna. "The Elusiveness of Reality: The Limits of Cognition in Katherine Mansfield's Short Stories." Katherine Mansfield and Literary Modernism, edited by Janet Wilson et al., Continuum, 2011, pp. 67-77.

Lee, Vernon. The Beautiful. Cambridge University Press, 1913.

Lee, Vernon. Laurus Nobilis: Chapters on Art and Life. John Lane, The Bodley Head, 1909.

Levine, Caroline. Forms: Whole, Rhythm, Hierarchy, Network. Princeton University Press, 2015.

Lakoff, George and Mark Johnson. Metaphors We Live By. University of Chicago Press, 2003.

Mansfield, Katherine. “Miss Brill.” Garden Party and Other Stories. Penguin, 1997, pp. 110-14.

Marcussen, Marlene Karlsson. Reading for Space: An Encounter between Narratology and New Materialism in the Works of Virginia Woolf and Georges Perec. PhD dissertation, University of Southern Denmark, 2016. 
Martin, Kirsty. Modernism and the Rhythms of Sympathy: Vernon Lee, Virginia Woolf, D.H. Lawrence. Oxford University Press, 2013.

New, William H. Reading Mansfield and the Metaphors of Form. McGill-Queen's University Press, 1999.

Stanica, Miruna. "Bundles, Trunks, Magazines: Storage, Aperspectival Description, and the Generation of Narrative.” Style, vol. 48, no. 4, 2014, pp. 513-28.

Titchener, Edward B. A Text-Book of Psychology. Macmillan, 1913.

Woolf, Virginia. “The New Dress.” A Haunted House. Hogarth Press, 1953, pp. 43-48.

Zahavi, Dan. "Empathy and Other-Directed Intentionality." Topoi, vol. 33, no. 1, 2014, pp. 129-42.

Zahavi, Dan, and Philippe Rochat. "Empathy $\neq$ Sharing: Perspectives from Phenomenology and Developmental Psychology." Consciousness and Cognition no. 36, 2015, pp. 543-53. 